\title{
OUTCOME OF SCLEROSING AGENT FOR MANAGING THE ORAL PYOGENIC GRANULOMA.
}

1. BDS, RDS, MSc Postgraduate Student of Oral Maxillofacial Surgery LUMHS Jamshoro.

2. BDS, FCPS, FFDRCSI Associate Professor Oral Maxillofacial Surgery LUMHS Jamshoro.

3. BDS, RDS, MSc Postgraduate Student of Oral Maxillofacial Surgery LUMHS Jamshoro.

4. BDS, RDS, MSc Lecturer Operative Dentistry LUMHS Jamshoro.

5. BDS, RDS, MSc Postgraduate Student of Ora Maxillofacial Surgery LUMHS Jamshoro.

6. BDS, RDS, FCPS

R-2 Resident of Operative Dentistry LUMHS Jamshoro.

Correspondence Address:

Dr. Ameer Gul Zardari

Department of Oral Maxillofacial Surgery

LUMHS Jamshoro.

ameergulzardari83@gmail.com

Article received on:

16/09/2019

Accepted for publication:

$11 / 12 / 2019$

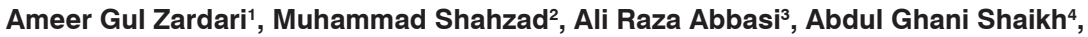
Aftab Ahmed Memon ${ }^{5}$, Noorullah Jagirani ${ }^{6}$

ABSTRACT... Objectives: Outcome of sclerosing agent for managing the oral pyogenic granulomain terms of post-operative pain, post-operative healing and post-operative infection. Study Design: Cross-section study. Setting: Department of Oral \& Maxillofacial Surgery, Institute of Dentistry, Liaquat University of Medical \& Health Sciences Jamshoro / Hyderabad. Period: October 2018 to March 2019. Material \& Methods: Patients with oral pyogenic granuloma and willing to contribute in study were included. Sclerosing agent (ethanolamine oleate) was taken in 3cc disposable syringe and injected in each lesion once a week and repeated according to need. Patients were fooled for 1 to 3 weeks. Outcome was assessed in terms of post-operative pain, post-operative healing and post-operative infection. Data was recorded in proforma. Results: Total seventy four patients were included; their mean age was $40.67+4.99$ years. Males were in majority $59.5 \%$. On $1^{\text {st }}$ week 32 showed mild pain which was markedly decreased on $2^{\text {nd }}$ and $3^{\text {rd }}$ week almost among all patients. On $1^{\text {st }}$ week healing was achieved by all cases. Infection was occurred in 4 patients and fever was noted in 12 cases. On $2^{\text {nd }}$ week infection was occurred in 2 patients and fever was in 04 cases. On $3^{\text {rd }}$ week infection was noted in only one cases and fever not found. Conclusion: It was concluded that sclerosing agent ethanolamine oleate is better treatment option than surgical removal with lower postoperative pain, best achievement of post-operative healing and lower rate of post-operative infection for the oral pyogenic granuloma management.

Key words: $\quad$ Ethanolamine Oleate, Oral Pyogenic Granuloma, Sclerosing Agent, Sclerotherapy.

Article Citation: Zardari AG, Shahzad M, Abbasi AR, Shaikh AG, Memon AA, Jagirani N. Outcome of sclerosing agent for managing the oral pyogenic granuloma. Professional Med J 2020; 27(6):1224-1229.

DOI: 10.29309/TPMJ/2020.27.06.4164

\section{INTRODUCTION}

Oral pyogenic granuloma $(P G)$ is a reactive inflammation filled with undeveloped fibroblastic connective tissue, proliferating vascular channels and scattered inflammatory cells. ${ }^{1}$

Oral PGs mostly comprise of lobular masses of hyperplastic granulation tissues in addition to endothelial proliferation as well as union of inflammatory infiltrates. Surface is generally, smooth, lobulated, pedunculated or sessile and soft to palpation frequently erodes that leads to bleeding and pain which are highly common problems correlated with oral PG. ${ }^{2}$

Surface of oral PG varies from purple to red to pink in color with size infrequently exceed from

\section{5 centimeters in size. ${ }^{3}$}

PG of buccal cavity is believed to involve the gingiva usually, extra-gingival that takes place on the buccal mucosa, cheeks, palate, lips and tongue. ${ }^{4}$

Oral PG takes place due to low grade, chronic, trauma, local irritants, and traumatic injury, chronic irritation by the calculus, drugs such as Cyclosporine or Hormonal factors. ${ }^{5}$

There are many treatment choices for oral PG that is sclerotherapy, $\mathrm{co}_{2}$ laser therapy, curettage and surgical removal. Surgical removal is made with scalpel and blade no: 15 timely diagnosis of $P G$ and surgical therapy with sufficient excision 
is a safe and benefits of no recurrence rates and beneficial for patients to free from repeated visits. ${ }^{6}$ Though in these both processes is get defining clear benefits of one over the others. In surgical removal results in little bleeding and cosmetic problems. ${ }^{7} \mathrm{~S}$

Sclerotherapy is a process of targeted eradication of small varicose veins, vessels and vascular abnormalities by injections of sclerosing agents. ${ }^{8}$ There are various sclerosing agents used for sclerotherapy such as such as $5 \%$ Phenol in Arachus and almond oil, Phenol in, Aetoxisclerol, Ethanolamine oleate, Polidocanol, Quinine, Sodium tetradecylsulphate, XiaoZhilign(XZL), Absolute alcohol and Hypertonic saline have been used in sclerotherapy. ${ }^{9}$

The efficacy of sclerosing agent ethanolamine oleate was assessed for the treatment of oral $P G$ and treatment effects were determined $P G$ removed completely. ${ }^{10}$ Ethanolamine oleate is practiced as a sclerosing agent with disposable syringe for the oral PG treatment. The mean number of ethanolamine oleate injections is 1 which ranges from 1 to 4 injections as per size of oral PG. Treatment with PG can possibly result repeated visits mainly in large variety, as it is associated with $95 \%$ cure rate. So likelihoods of recurrence are there..$^{11-12}$ No such local data was found in literature, therefore this study has been conducted to assess the efficacy of sclerosing agent for managing the oral pyogenic granuloma in terms of post-operative pain, post-operative healing and post-operative infection.

\section{MATERIAL \& METHODS}

This cross-section study was performed at department of Oral \& Maxillofacial Surgery, Institute of Dentistry, Liaquat University of Medical \& Health Sciences Jamshoro / Hyderabad, from October 2018 to March 2019. All the patients with age between 18-45 years, patients having oral $P G$ and willing to contribute in the study were included. All the patients underwent emergency process, patients having any systemic disease which hampers the surgical intervention on the basis of previous history and clinical record, any pathological lesion in the buccal cavity, mentally retarded patients and pregnant women were excluded. Informed consent was taken from every patient. The oral PG was diagnosed by history, clinical examinations and periapical x-ray. Clinical and demographic parameters such as age, gender, site of oral PG were recorded in proforma. All surgical process of oral PG was achieved under local anesthesia through infiltration neighboring deep the oral PG by xylocaine $2 \%$ with adrenaline. All the patients underwent sclerosing agent by 3 cc disposable syringe and Cotton balls. In the course of injecting the ethanolamine oleate bevel position of syringe was maid and applies local compression following injection with cotton balls. Following application of inj. ethanolamine oleate, patients were prescribing Acetaminophen 500 mg 8 hourly. Patients were followed for 1 week, 2 weeks and 3 weeks to access complications as; post-operative pain, post-operative healing and post-operative infection. All the data was recorded in proforma analysis was done by using SPSS (statistical package for social services) version -20.

\section{RESULTS}

Total 74 patients studied, with a mean age $40.67+4.99$ years. Males $44(59.5 \%)$ were in majority contrasted to $30(40.5 \%)$ females. Table-I

On $1^{\text {st }}$ week assessment, 42 patients were without pain and 32 were with mild pain. On second week assessment pain was markedly decreased only 4 patients exhibited mild pain. On $3^{\text {rd }}$ week pain was decreased almost in all cases only 1 patients exhibited mild pain. Table-II.

On $1^{\text {st }}$ week healing was achieved by all cases. Infection was occurred in 4 patients and fever was noted in 12 cases. On $2^{\text {nd }}$ week infection was occurred in 2 patients and fever was noted in 04 cases. On $3^{\text {rd }}$ week infection was noted in only one cases and fever not found. Table-III. 


\begin{tabular}{|l|c|c|}
\hline \multicolumn{1}{|c|}{ Variables } & Frequency & Percentage \\
\hline Gender & & \\
\hline Male & 44 & $59.5 \%$ \\
\hline Female & 30 & $40.5 \%$ \\
\hline Total & 74 & $100 \%$ \\
\hline AGE (mean+SD) & \multicolumn{2}{|c|}{$40.67+4.99$ years } \\
\hline Occupation & \multicolumn{2}{|c|}{} \\
\hline Worker & 14 & $18.92 \%$ \\
\hline Fisher men & 4 & $5.41 \%$ \\
\hline Farmer & 18 & $24.32 \%$ \\
\hline Housewife & 14 & $18.92 \%$ \\
\hline Shopkeeper & 14 & $18.92 \%$ \\
\hline Ward servant & 4 & $5.41 \%$ \\
\hline Carpenter & 4 & $5.41 \%$ \\
\hline Plumber & 2 & $2.70 \%$ \\
\hline Police man & 0 & $0 \%$ \\
\hline Malhi & 0 & $0 \%$ \\
\hline Student & 0 & $0 \%$ \\
\hline Total & & \\
\hline & & \\
\hline Table & & \\
\hline
\end{tabular}

Table-I. Age, gender and occupational distribution of patients $n=74$

\begin{tabular}{|l|c|}
\hline \multicolumn{1}{|c|}{ Pain } & Frequency (\%) \\
\hline $\mathbf{1}^{\text {st }}$ week & \\
\hline No & $42(56.76 \%)$ \\
\hline Mild & $32(43.24 \%)$ \\
\hline Moderate & $0(0 \%)$ \\
\hline Severe & $0(0 \%)$ \\
\hline Total & $74(100 \%)$ \\
\hline $2^{\text {nd }}$ week & \\
\hline No & $70(94.59 \%)$ \\
\hline Mild & $4(5.41 \%)$ \\
\hline Moderate & $0(0 \%)$ \\
\hline Severe & $0(0 \%)$ \\
\hline Total & $74(100 \%)$ \\
\hline $3^{\text {rd }}$ week & \\
\hline No & $73(98.6 \%)$ \\
\hline Mild & $1(1.4 \%)$ \\
\hline Moderate & $0(0 \%)$ \\
\hline Severe & $0(0 \%)$ \\
\hline Total & $74(100 \%)$ \\
\hline
\end{tabular}

Table-II. 1 st week to $3^{\text {rd }}$ week pain of patients $n=74$

\begin{tabular}{|l|c|}
\multicolumn{1}{|c|}{ Variables } & Frequency (\%) \\
\hline $\mathbf{1}^{\text {st }}$ week & \\
\hline Infection & $4(5.41 \%)$ \\
\hline Fever & $12(16.22 \%)$ \\
\hline $\mathbf{2}^{\text {nd }}$ week & \\
\hline Healing & $74(100 \%)$ \\
\hline Infection & $2(2.7 \%)$ \\
\hline Fever & $4(5.4 \%)$ \\
\hline $\mathbf{3}^{\text {rd }}$ week & \\
\hline Healing & $74(100 \%)$ \\
\hline Infection & $1(1.4 \%)$ \\
\hline Fever & $0(0 \%)$ \\
\hline \multicolumn{1}{|c|}{ Table-III. 1st week to $3^{\text {rd }}$ week complications and } \\
& healing of patients $\mathbf{n = 7 4}$ \\
\hline
\end{tabular}

\section{DISCUSSION}

A pyogenic granuloma is granuloma is inflammatory, benign hyperplasia of mucous membrane and skin. ${ }^{13}$ The gingiva is renowned for the growth of PGs as the most prevalent intraoral site. Furthermore, they also frequently affect children's and young adults' buccal mucosa, lips, and tongues. ${ }^{14}$ Although the most commonly used technique for treatment of $P G$ is surgical excision, many other methods including elimination with electric scalpel or cryosurgery cauterization by silver nitrate, sclerotherapy by monoethanolamine oleate and sodium tetradecyl sulfate, ${ }^{15}$ absolute ethanol injection dye, ligation ${ }^{16}, \mathrm{CO} 2$ laser and $\mathrm{Nd}: Y A G$, laser photocoagulation, and shave excision have been reported to be used for this purpose. Surgical excision has been reported to have $16 \%$ rate of recurrence in treatment of PG. This study was a first comparative study which was conducted to compare the outcomes of surgical removal versus sclerosing agent for the management of oral PG. In this study sclerosing agent ethanolamine oleate showed best outcome as compare to surgical removal. Similarly Samantha et al. ${ }^{17}$ presented a case series on oral pyogenic granulomas wherein four cases showed complete resolution and one fibrosed on treating with sclerosing agent. In reactive vascular lesions, Hong et al $^{18}$ assessed the effectiveness of sclerotherapy by using ethanolamine oleate. 16 cases out of 21 were seen with pyogenic granuloma and they reached clearance of 95 percent. Matsumoto 
et $\mathrm{al}^{19}$ utilized sclerotherapy among 9 PG cases and all the subjects demonstrated complete clearance.

Because PGs are the benign vascular lesions, the application of intra lesion sclerosing agents have been indicated in few literatures as the least costly medical therapy agents for PG. Often, surgical procedure can be prevented or mitigated by sclerotherapy. The implementation of a simple method in a third world country including Nepal will be quite helpful for all patients, where it is a problematic situation for all subjects to attend a tertiary clinic. When dentists are educated in rural areas with this easy procedure, patients' morbidity can be reduced. The advantages of sclerotherapy are that it is a simple, safe, effective, and minimally invasive procedure, with minimal discomfort to the patient and minimal complications compared to surgery. There is negligible blood loss and no requirement for any postoperative dressing or specific care. ${ }^{20,21}$ In comparison to our results, Study conducted by Shah JS et al ${ }^{22}$ reported in their results that Surgical resection of the lesion is the mainstay treatment of mucocele and pyogenic granuloma. However intraoperative bleeding, postoperative infection and recurrence chances are more with surgical technique. In addition, surgical therapy might be difficult for infants and children under local anesthesia. They advised that to avoid complications associated with surgical procedures; sclerotherapy has been reported to have the advantages of minimal scarring, little recurrence, and few complications in the treatment of mucocele and pyogenic granuloma compared with other procedures.

In this series mean age was 40.67 years. Kiran Ret $\mathrm{al}^{23}$ reported 28 years of mean age of patients. Other studies also found small age as compare to our findings as a Brazilian study in 293 cases, found 27 years of mean age. PG can manifest at any age, however $>50$ percent of cases were reported between 10 and 40 years of age, with peak effects at the age of 30 years. ${ }^{24}$ This mean age difference may because age of our study was higher as compare to these studies. In this study males were found in majority. Similarly Kiran Ret $\mathrm{al}^{25}$ reported $42.9 \%$ male cases and $57.1 \%$ female cases. While in other studies reported that females were most common. Similar findings were also reported by Mohamed Zaghlool Amer et al. ${ }^{26}$ on other hand Khaitan $\mathrm{T}$ et $\mathrm{al}^{27}$ reported that females were most common as compare to males. Samatha $Y$ et $\mathrm{al}^{17}$ reported that females are found to be more frequently affected with a predilection of 3:2 over male. This difference may because in our study female with only oral PG were included. According to the other studies the management of pyogenic granulomas comprises conservative surgery, cryosurgery, or a laser surgery generally adequate but often results in scars, recurrence, and skilled expertise. ${ }^{27,28}$ Therefore, sclerotherapy was considered as an alternative and effective treatment modality. Sclerotherapy is described as the targeted eradication of vascular anomalies and anomalies of varicose veins and small vessels via sclerosant injection. ${ }^{27}$ These are tissue aggravations causing endothelial damage and vascular thrombosis resulting in endofibrosis and vascular obliteration when injected into or adjacent to blood vessels. ${ }^{8}$

\section{CONCLUSION}

It was concluded that sclerosing agent ethanolamine oleate is a better treatment option than surgical removal. It has a lower rate of pain, best achievement of post-operative healing and lower rate of post-operative infection for the management of oral PG.

Copyright@ 11 Dec, 2019.

\section{REFERENCE}

1. Iyer $\mathrm{VH}$, Sasikumar $\mathrm{R}$. Management of oral pyogenic granuloma with $940 \mathrm{~nm}$ diode laser: A rare case report. Int J Las Dent 2013; (3):100.

2. Al-shiaty RA, Ottoman BA. Recurrent pyogenic granuloma: An update. Int J Sci Rep 2015; 1(1):22-31.

3. Jafarzadeh $H$, Sanatkhani $M$, Mohtasham $N$. Oral pyogenic granuloma: A review. J Oral Sci 2006; 48(4):167-75.

4. Kamal R, Dahiya P, Puri A. Oral pyogenic granuloma: Various concepts of etiopathogenesis. J Oral MaxillofacPathol 2012; 16(1):79.

5. Chandrashekar B. Minimally invasive approach to eliminate pyogenic granuloma: A case report. Case reports in dentistry 2012; 26:2012. 
6. Narendra S, Bose C, Rout N. Oral pyogenic granuloma: One reactive hyperplastic lesion of the gingiva. Int $\mathrm{J}$ Res Med Sci 2015; 3: 3863-8.

7. Joda T. Esthetic management of mucogingival defects following total excision in acase of pyogenic granuloma. Eur J Esthet Dent. 2012; 1(7):110-119.

8. Sacchidanand S, Purohit V. Sclerotherapy for the treatment of pyogenic granuloma. Indian J Dermatol 2013; 58 (1):77.

9. Chauhan VF, Patel K, Anchalia MM. Prospective coparitive study of sclerotherapy by hypertonic saline and absolute alcohol for the treatment of haemorrhoides. Gujrat Med J 2014; 69(1):82-6.

10. Matsumoto $K$, Nakanishi $H$, Seike T, Koizumi $Y$, Mihara $\mathrm{K}$, Kubo Y. Treatment of pyogenic granuloma with a sclerosing agent. DermatolSurg 2001; 1(6):521-3.

11. Hong SK, Lee HJ, Seo JK, Lee D, Hwang SW, Sung HS. Reactive vascular lesions treated using ethanolamine oleatesclerotherapy. Dermatol Surg. 2010; 1 (7):11481152.

12. Cai Y, Sun R, He KF, Zhao YF, Zhao JH. Sclerotherapy for the recurrent granulomatous epulis with pingyangmycin. Med Oral Patol Oral Cir Bu- cal. 2017 Mar 1; 22 (2):e214-8.

13. Jafarzadeh $H$, Sanatkhani $M$, Mohtasham $N$. Oral pyogenic granuloma: A review. J Oral Sci. 2006;48:167-175

14. Pagliai KA, Cohen BA. Pyogenic granuloma in children. Pediatr Dermatol. 2004;21:10-13

15. Matsumoto K, Nakanishi H, Seike T, Koizumi Y, Mihara $\mathrm{K}$, Kubo Y. Treatment of pyogenic granuloma with a sclerosing agent. Dermatol Surg. 2001 Jun; 27(6):5213.

16. Ichimiya $M$, Yoshikawa $Y$, Hamamoto $Y$, Muto $M$. Successful treatment of pyogenic granuloma with injection of absolute ethanol. J Dermatol. 2004 Apr; $31(4): 342-4$.

17. Samatha $Y$, Reddy $T H$, Jyothirrmai, Ravikiran A, Sankar AJ. Management of oral pyogenic granuloma with sodium tetra decylsulphate. A case series. N Y State Dent J 2013; 79:55-7
18. Hong SK, Lee HJ, Seo JK, Lee D, Hwang SW, Sung HS. Reactive vascular lesions treated using ethanolamine oleatesclerotherapy. Dermatol Surg. 2010; 36:114852.

19. Moon SE, Hwang EJ, Cho KH. Treatment of pyogenic granuloma by sodium tetradecylsulphatesclerotherapy. Arch Dermatol. 2005;141:645-6

20. Khaitan T, Sinha R, Sarkar S, Kabiraj A, Ramani D, Sharma $M$. Conservative approach in the management of oral pyogenic granuloma by sclerotherapy. J Indian Acad Oral Med Radiol 2018; 30:46.

21. Reddy GS, Reddy GV, Reddy KS, Priyadarshini BS, Sree PK. Intralesionalsclerotherapy - A novel approach for the treatment of intraoral haemangiomas. J ClinDiagn Res 2016; 10:ZD13-4.

22. Shah JS, Ranghani AF. Sclerotherapy in pyogenic granuloma and mucocele. J Indian Acad Oral Med Radiol 2018;30:230-4

23. Kiran R, Asad F, Haider S, Bashir B, Rani Z, Khurshid $\mathrm{K}$, Pal SS. Efficacy of sclerotherapy with sodium tetradecylsulphate in the treatment of pyogenic granuloma. Journal of Pakistan Association of Dermatology. 2018 Jul 11; 27(2):110-3.

24. Gordón-Núñez MA, de Vasconcelos Carvalho $M$, Benevenuto TG, Lopes MFF, Silva LMM, Galvão HC. Oral pyogenic granuloma: A retrospective analysis of 293 cases in a Brazilian population. J Oral Maxillofac Surg. 2010;68:2185-8

25. Rai S, Kaur M, Bhatnagar P. Laser: A powerful tool for treatment of pyogenic granuloma. J CutanAesthet Surg. 2011;4:144-7

26. Mohamed ZaghloolAmer, Hamdy Abdelmageed Marzouk and Ibrahim Mohamed Elsharabasy. Impact of diode laser versus sclerotherapy in treatment of oral pyogenic granuloma. J Am Sci 2016; 12(8):1-8]

27. Khaitan T, Sinha R, Sarkar S, Kabiraj A, Ramani D, Sharma $M$. Conservative approach in the management of oral pyogenic granuloma by sclerotherapy. Journal of Indian Academy of Oral Medicine and Radiology. 2018 Jan $1 ; 30(1): 46$. 


\begin{tabular}{|c|l|l|l|}
\multicolumn{3}{|c|}{ AUTHORSHIP AND CONTRIBUTION DECLARATION } \\
\hline Sr. \# & \multicolumn{1}{|c|}{ Author(s) Full Name } & \multicolumn{1}{|c|}{ Contribution to the paper } & Author(s) Signature \\
\hline 1 & Ameer Gul Zardari & $\begin{array}{l}\text { Data collection, and } \\
\text { manuscript. } \\
\text { Manuscript review. }\end{array}$ \\
\hline 3 & Ali Raza Abbasi & Contribution in data analysis. & \\
\hline 4 & Abdul Ghani Shaikh & $\begin{array}{l}\text { Contribution in manuscript } \\
\text { writing. } \\
\text { Review of literature. }\end{array}$ \\
\hline 6 & Aftab Ahmed Memon & Noorullah Jagirani & Contribution in data analysis. \\
\hline
\end{tabular}

